\title{
The Effect of Glycopyrrolate on the Course of Symptomatic Duodenal Ulcer
}

\author{
Hector Trevino, M.D., Juan Anderson, M.D. $\dagger$ \\ Paula G. Davey, M.D., + and Keith S. Henley, M.D.
}

$I^{T}$ HAS BEEN SHOWN by Sun $^{1}$ that the administration of glycopyrrolate 1 (Robinul) to patients with duodenal ulcer results in a lowered incidence of symptomatic recurrences. Since there is a lack of controlled studies evaluating the effectiveness of therapeutic regimens on the long-term course of duodenal ulcer, it was decided to repeat the studies of Sun.

\section{METHODS}

The records of patients admitted to the Veterans Administration Hospital of Ann Arbor for the years 1953 to 1964 and diagnosed as suffering from duodenal ulcer were examined. Patients who had definitive operations for the relief of ulcer were excluded. The remainder were sent a letter outlining the objective of the study and were invited to participate provided they had suffered from significant ulcer symptoms during the previous year. Patients who responded were admitted to the Veterans Administration Hospital for a period of 5 days. During this period their clinical status was evaluated, and the duration and intensity of ulcer symptoms during the recent past was ascertained. An upper gastrointestinal tract X-ray examination was performed. If the patients' symptoms were compatible with duodenal ulcer and if, in addition, they showed significant duodenal bulb deformity, a duodenal ulcer crater, or both, they were admitted to the study. Patients were then placed on the study protocol and during their stay in the hospital received glycopyrrolate in increasing doses to a maximum of $2 \mathrm{mg}$. 3 times per day or until tolerance was reached. In general this required 2 tablets ( $1 \mathrm{mg}$. per tablet) 3 times a day. Care was taken to ascertain that in the doses used, side effects were present but minimal. Upon discharge from the hospital each patient was given a

From the Department of Internal Medicine, Section of Gastroenterology, University of Michigan Medical School, and the Veterans Administration Hospital, Ann Arbor, Mich.

Our thanks are due to the A. H. Robins Co., Richmond, Va. for the supply of tablets and for a grant in aid of this study. We also wish to thank Dr. W. A. Sodeman for his cooperation, and Mrs. H. Waite for clerical assistance.

* Fellow in Gastroenterology of the W. K. Kellogg Foundation, Battle Creek, Mich. Present address: Department of Medicine, Facultad de Medicina de la Universidad de Nuevo Leon, Monterrey, N. L., Mexico.

+Fellow in Gastroenterology. Present address: Hospital de Clinicas-Sala IV, Universidad de Buenos Aires, Buenos Aires, Argentina.

†Present address: St. Joseph's Mercy Hospital, Ann Arbor, Mich. 
study number, and a supply of tablets identified by the study number was set aside in the pharmacy of the hospital. These tablets either contained glycopyrrolate in closes of $1 \mathrm{mg}$. per tablet or a placebo, (a mixture of calcium phosphate, carbowax. starch, lactose, and magnesium stearate). In addition each tablet contained $2.5 \mathrm{mg}$. of riboflavin, an amount sufficient to impart a deep yellow color to the urine particularly evident when examined with an ultraviolet lamp. A similar procedure has recently been described by Jones." Assignment to drug and placebo groups was on a double-blind basis. The code was kept sealed in the pharmacy of the hospital. (To conform with interstate shipping requirements, each bottle was doubly labeled, the outer label identified the drug, the inner label indicated the study number of the patient. Upon the arrival of the shipment the outer label was removed by the secretarial staff in the absence of any of the investigators).

After discharge from the hospital patients were seen at intervals of 6 weeks. On each visit a routine symptomatic inquiry and physical examination were carried out. The incidence of gastrointestinal symptoms, their duration, and intensity were noted. Absence from work attributed to ulcer disease was documented. The impression of both the examiner and the patient regarding the effectiveness of treatment was recorded. The urine was examined to determine whether the patient was taking the drug. The need for antacids was ascertained. Patients were discouraged from taking anticholinergic medications other than those which may have been contained in the tablets provided. All patients were instructed to cease taking possible ulcerogenic drugs such as salicylates, and to avoid the use of tobacco and alcohol. They were further encouraged to pursue a 6-feeding program. These instructions were reiterated on each visit.

Each patient was followed in this manner for 18-27 months. When all patients had been discharged, the response to treatment over the entire period was assessed independently by two of us (J.A. and K.S.H.). According to this evaluation the patients who had been followed throughout the period of observation were assigned to 1 of 3 groups: "improvement," "no change," or "worse." The over-all impression was based on symptoms, complications, loss of working time, and the evaluation of patient and examiner as recorded on each visit. This was then compared with the patterns of the patient prior to entering the trial. Both observers agreed independently on all but 2 of the patients. (One patient eventually placed in the "improved" group received the drug, and 1 patient eventually placed in the "no change" group received placebo.) All patients who received surgical correction of their duodenal ulcer during the period of study were assigned to the "worse" category. After each patient had been finally assigned, the code was broken and the results evaluated.

\section{RESULTS}

A total of 151 patients were considered. After examination in the hospital 59 entered the study. The majority of the 92 patients thus excluded failed to 
answer the initial invitation; a few were found not to have significant ulcer symptoms or demonstrable ulcer disease. Thirteen patients failed to attend for follow-up ( 5 received the drug, the remainder the placebo). The remaining 46 could be evaluated. All those who remained in the study took the medication, as shown by urinary fluorescence.

The results are summarized in Table 1. There was no significant difference attributable to the drug. To exclude the possibility that chance differences in age, duration of symptoms, incidence of complications, or associated diseases (diabetes mellitus, chronic bronchitis, arteriosclerotic heart diseases) may have influenced the results, these facts were recorded separately. These data are summarized in Table 2. The mean age was virtually the same in all 3 groups, and comparable in its distribution between the "improved" and "worse" groups. Although the difference was not statistically significant, the duration of symptoms in those who were improved and received the drug was longer compared with those who improved and received the placebo. As our results were different from those reported previously, the data from our patients were compared with those reported by Sun. ${ }^{1}$ Both series described a population of males using the facilities of a Veterans Administration Hospital, and therefore are not necessarily representative of the duodenal ulcer population as a

TABLE 1. RESPONSE TO GLYCOPYRROLATE

\begin{tabular}{lccc} 
& Drug & Placebo & Total \\
\hline Improved & 14 & 11 & 25 \\
Worse & 8 & 8 & 16 \\
No change & 4 & 1 & 5 \\
$\quad$ TotaL & 26 & 20 & 46 \\
\hline
\end{tabular}

Chi ${ }^{2}$ was $0.05 ; \mathrm{p}>0.90$.

TABLE 2. RESPONSE RELATED TO AGE, DURATION OF SYMPTOMS, COMPLICATIONS, AND ASSOCIATED DISEASES

\begin{tabular}{|c|c|c|c|c|c|}
\hline & $\begin{array}{l}\text { Age } \\
(y r .)\end{array}$ & $\begin{array}{l}\text { Duration of } \\
\text { symptoms } \\
\text { (yr. })\end{array}$ & $\begin{array}{c}\text { Complications } \\
\text { due to } \\
\text { ulcer }\end{array}$ & $\begin{array}{c}\text { Associated } \\
\text { diseases }\end{array}$ & $\begin{array}{l}\text { Total No. } \\
\text { of pati nts }\end{array}$ \\
\hline \multicolumn{6}{|c|}{ IMPROVED } \\
\hline Drug & $49.3 \pm 11.2$ & $16.2 \pm 8.8$ & 5 & 6 & 14 \\
\hline Placebo & $53.7 \pm 12.5$ & $13.4 \pm 8.5$ & 6 & 6 & 11 \\
\hline \multicolumn{6}{|c|}{ WORSE } \\
\hline Drug & $55.7 \pm 13.3$ & $13.6 \pm 8.9$ & 3 & 7 & 8 \\
\hline Placebo & $51.3 \pm 11.2$ & $16.2 \pm 8.1$ & 3 & 5 & 8 \\
\hline \multicolumn{6}{|c|}{ NO CHANGE } \\
\hline Drug & $57.2 \pm 17.11$ & $23.0 \pm 17.1$ & 3 & 1 & 4 \\
\hline Placebo & 31 & 7 & 1 & 0 & I \\
\hline
\end{tabular}


TABLE 3. COMPARISON OF PRESENT AND EARLIER STUDIES (ALL PATIENTS)

\begin{tabular}{lcccc}
\hline & & $\begin{array}{c}\text { Duration of } \\
\text { symptoms } \\
\text { (years) }\end{array}$ & $\begin{array}{c}\text { Complications due to ulcer } \\
\text { before entering study }\end{array}$ \\
\cline { 5 - 5 } Sun & Age (years) & No./total & $\%$ \\
\hline This series & $38.6 \pm 9.3$ & $9.2 \pm 5.9$ & $32 / 37$ & 87 \\
\hline & $52.1 \pm 14.6$ & $15.2 \pm 10.9$ & $26 / 46$ & 57 \\
\hline & $\mathrm{p}<0.001$ & $\mathrm{p}<0.001$ & \multicolumn{2}{c}{$\mathrm{p}<0.0 \mathrm{I}$} \\
\hline
\end{tabular}

who e. The age distribution, duration of the disease, and the incidence of complications prior to treatment in the series reported by Sun and in our study is shown in Table 3 . The patients studied by Sun were significantly younger and their symptoms had been present for a shorter period of time. On the other hand, the incidence of complications prior to the start of therapy was higher in Sun's series $(86 \%)$ compared with ours $(57 \%)$. In our series one compication occurred in the course of therapy (hemorrhage in one of the patients receiving the placebo). Serious complications occurred in 10 of 17 patients receiving the placebo in the patients described by Sun compared with only 1 of 20 receiving the drug. The patients studied by us were therefore older, had their disease for a longer period of time, and were less prone to complications.

\section{DISCUSSION}

There is a recognized need for an effective therapeutic regimen which prevents recurrence of symptoms and disability in patients with known duodenal ulcer who have been treated successfully during the initial episode which led to diagnosis. The observations of $\operatorname{Sun}^{1}$ have suggested that glycopyrroiate may be of significant benefit in meeting this need. Our observations have not confirmed this, and the reasons for this difference in results are not clear.

Both series employed different means of ensuring that the patients were receiving their medications. Our patients were unlikely to recognize the objective of the examination of the urine. On the other hand, our method of assessment only indicated that the drug had been taken immediately before the outpatient visit. The method employed by Sun (i.e., counting of the remaining tablets at each visit) is obviously capable of manipulation by the patient and the purpose of this method of assessment is more easily recognized. Neither procedure, therefore, is entirely free from possible error, but both series agree that virtually all the patients consumed the medication provided.

In both series the duration of symptoms in those who received the drug was slightly longer than those who received the placebo, although in neither instance was this statistically significant. This argues against the hypothesis that failure to respond to the drug might have been due to chronicity as 
implied by longer duration of symptoms. It therefore became important to determine whether the 2 series were comparable in other respects. There were significant differences in the 2 series in age, duration of symptoms, and incidence of complications. In this series we report patients who were older, whose disease had been present for a longer period of time, and who were less prone to develop complications either before or during the course of observation. As both series were selected from patients who had not been treated surgically, this may reflect differences in policy between the 2 hospitals. It is likely that many of the patients studied by Sun would have been treated surgically in this institution. Furthermore, our hospital serves a large and, at least in part, rural area of Michigan, and many patients are living at some distance from the hospital. The Mount Alto Veterans Administration Hospital is located in the center of a large urban area and presumably serves such a population. This suggests the selectiveness inherent in any sample reported from one institution. It is therefore possible that younger patients whose ulcers are less chronic and who are liable to acute exacerbations while still maintaining the ability to heal their ulcers, are more likely to respond to glycopyrrolate or similar drugs as compared with older groups of patients with more chronic ulcers less likely to suffer from acute exacerbations and less likely to heal.

In this series a small number of patients showing "no change" have been separated from those who were regarded as improved and those in whom treatment was considered to have failed. This represents a category not reported by Sun. The classification became necessary because in 5 patients the pattern of symptoms had not changed while under observation. There is little justification for including such patients in the "failure" group because administration of the drug may have prevented the natural progression of the disease. On the other hand, as these patients were not improved they could not reasonably be regarded as having benefited by the treatment.

\section{SUMMARY}

A double-blind controlled study of the effect of glycopyrrolate on 46 patients with duodenal ulcer is reported.

No beneficial effect of the drug over a period of 18-27 months could be demonstrated. Possible reasons for the difference between this study and that reported previously are discussed.

K. S. H.

Department of Internal Medicine University of Michigan Medical School Ann Arbor, Mich. 48104

\section{REFERENCES}

1. SuN, C. H. Long term anticholinergic therapy for prevention of recurrences in duodenal ulcer. Amer J Dig Dis 9:706, 1964.

2. Jones, I. H. Riboflavine as an indicator of drug taking behavior. Med J Aust 1:5, 202, 1967. 